\title{
Jogo de tabuleiro: uma tecnologia educativa sobre sinais do transtorno do espectro do autismo
}

\author{
Board game: an educational technology about signs of autism spectrum disorder \\ Juego de mesa: una tecnología educativa sobre los signos del trastorno del espectro autista \\ Raquel Cristina Sulzbach ${ }^{1}$ (1) https://orid.org/0000-0002-1062-375x) \\ Lucimare Ferraz ${ }^{1}$ (1) htps://orcid.org/0000-0002-2487-8614) \\ Leila Zanatta ${ }^{1}$ (1) https://orcid.org/0000-0003-0935-4190) \\ Junir Antonio Lutinski ${ }^{1}$ (I) https://orcid.org/0000-0003-0149-5415)
}

\section{Resumo}

Objetivo: Desenvolver, validar e avaliar um jogo de tabuleiro sobre os sinais de Transtorno do Espectro do Autismo (TEA) para Agentes Comunitários de Saúde (ACS) da Atenção Primária a Saúde (APS).

Métodos: Estudo metodológico realizado em três etapas: desenvolvimento, validação e avaliação, processo realizado de modo participativo. Os participantes deste projeto foram 25 trabalhadores da saúde.

Resultados: 0 jogo de tabuleiro construído consiste numa dinâmica de perguntas e respostas em que foi validado, obtendo um IVC geral de 0,9615 . Os participantes manifestaram uma experiência proveitosa com a tecnologia educacional, demonstrando ser informativo e instigante. Vale destacar, que a participação da equipe multiprofissional na pesquisa foi relevante para 0 aprimoramento do jogo de tabuleiro.

Conclusão: 0 Jogo de Tabuleiro "Identificando Sinais de Transtorno do Espectro do Autismo" demonstra ser uma tecnologia com potencial para os profissionais de saúde na linha do cuidado à criança portadora do TEA na APS.

\section{Abstract}

Objective: To develop, validate and evaluate a board game about the Signs of the Autism Spectrum Disorder (ASD) to Community Health Agents (CHA) of Primary Health Care (PHC).

Methods: a methodological study realized in three stages: development, validation and evaluation, a process realized in a participatory manner. The participants of this project were 25 health workers.

Results: The constructed board game consists in a dynamic of questions and answers that was validated, obtaining an overall CVI of 0.9615 . The participants expressed a profitable experience with an educational technology that was informative and thought-provoking. Worth mentioning that the participation of multidisciplinary team in the research was relevant to the improvement of the board game.

Conclusion: The Board Game "Identifying Signs of Autism Spectrum Disorder" proves to be a technology with potential for health professionals in the line of care for children with ASD in PHC.

\section{Resumen}

Objetivo: Desarrollar, validar y evaluar un juego de mesa sobre los signos del Trastorno del Espectro Autista (TEA) para Agentes de Salud Comunitarias.

Métodos: Estudio metodológico hecho en tres etapas: desarrollo, validación y evaluación, proceso hecho de modo participativo. Los participantes en este proyecto fueron 25 trabajadores de la salud.

Resultados: El juego de mesa desarrollado se basa en una dinámica de preguntas y respuestas en las que fue validado, obteniendo un IVC global de 0,9615. Los participantes expresaron una experiencia productiva con la tecnología educativa que según ellos ha sido informativa y al mismo tiempo estimulante. Es de destacar que la participación del equipo multidisciplinario en la investigación fue relevante para la mejora del juego de mesa. Conclusión: El Juego de Mesa “Identificando Signos de Trastorno del Espectro Autista” demuestra ser una tecnología con potencial para los profesionales de la salud en la línea de atención a los niños con TEA en la APS.
Descritores

Tecnologia educacional; Enfermagem pediátrica; Transtorno do espectro do autismo

Keywords

Educational technology; Pediatric nursing, Autism spectrum disorder

\section{Descriptores}

Tecnología educacional; Enfermería pediátrica; Trastorno del espectro autista

\section{Como citar:}

Sulzbach RC, Ferraz L, Zanatta L, Lutinski JA. Jogo de tabuleiro: uma tecnologia educativa sobre sinais do transtorno do espectro do autismo. Rev Soc Bras Enferm Ped. 2021;21(2):102-9.

\footnotetext{
${ }^{1}$ Universidade do Estado de Santa Catarina, Florianópolis, SC, Brasil.

Conflitos de interesse: nada a declarar.

Submetido: 14 de Julho de 2021 | Aceito: 3 de Dezembro de 2021

Autor correspondente: Raquel Cristina Sulzbach | E-mail: raquelcristina16@hotmail.com

DOI: http://dx.doi.org/10.31508/1676-379320210015
} 


\section{Introdução}

O Transtorno do Espectro do Autismo (TEA), de acordo com o Manual Diagnóstico e Estatístico de Transtornos Mentais, é um transtorno do neurodesenvolvimento, caracterizado por déficit na interação, comunicação social de maneira persistente, padrões de comportamentos restritos, repetitivos e estereotipados..$^{(1)}$ No Brasil, a prevalência dos casos de TEA teve um aumento significativo nos últimos anos. Dados da Organização Mundial da Saúde, mostram que uma em cada 160 crianças tem o diagnóstico de TEA,,$^{(2)}$ e a maioria das pessoas portadoras do TEA possui condições associadas ao transtorno, que também interferem na sua autonomia e na qualidade de vida, como ansiedade, distúrbios do sono, epilepsia, agressividade e irritabilidade. ${ }^{(3)}$

Nessa perspectiva é fundamental que a intervenção psicossocial baseada em evidências seja realizada de forma precoce, reduzindo assim, as dificuldades causadas por esse agravo, melhorando a qualidade de vida das pessoas com TEA, como também a de seus cuidadores/familiares. ${ }^{(2)}$ Para tanto, o profissional enfermeiro, tem um papel primordial na assistência à criança com esse agravo, pois a detecção precoce favorece um plano de cuidado adequado e permite um bom desenvolvimento. ${ }^{(4)}$ Dessa forma, tendo em vista de que são os Agentes Comunitários de Saúde (ACS), geralmente coordenados pelo profissional enfermeiro, que têm um papel extensionista nos serviços dentro da comunidade e uma postura vigilante para com as famílias, ${ }^{(5)}$ torna-se importante o desenvolvimento de uma tecnologia educativa para identificação precoce de sinais indicativos de TEA em crianças.

Para a qualificação dos ACS, que atuam na Atenção Primária a Saúde (APS), é primordial um processo de ensino e aprendizagem efetivo para que possam atuar frente as situações de diagnóstico de TEA.(6) Deste modo, o método de ensino baseado em jogos didáticos é uma alternativa que auxilia no desenvolvimento do raciocínio, habilidades e também incentiva o trabalho em equipe, além de facilitar o aprendizado do ACS, uma vez que os jogos educativos podem instigar discussões, melhorar a comunicação e promover habilidades de pensamento crítico. ${ }^{(7)}$

Considerando as inúmeras vantagens para o processo de aprendizagem e educação em saúde que o jogo de tabuleiro possibilita, realizou-se este estudo com objetivo de desenvolver, validar e avaliar um jogo de tabuleiro para os trabalhadores ACS que atuam na APS sobre os sinais de TEA em crianças.

\section{Métodos}

Trata-se de um estudo metodológico, que desenvolveu, validou e avaliou uma tecnologia educativa do tipo jogo de tabuleiro. Para a elaboração do produto foi utilizado o referencial de Teixeira (2020), que propõe o desenvolvimento da tecnologia educativa em três etapas: 1- produção/desenvolvimento; 2 - validação e 3avaliação. O processo ocorreu de modo participativo de primeira densidade. Essa modalidade também conhecida como participação de baixa intensidade, o público-alvo entra em contato com a tecnologia durante seu processo de elaboração, manifestando sua opinião sobre aspectos como objetivo, organização, estilo da escrita, aparência e motivação. ${ }^{(8)}$

Para o desenvolvimento do Jogo de Tabuleiro, a participação de uma equipe multiprofissional foi a estratégia adotada. Sendo que os critérios de inclusão foram: ser profissionais e trabalhadores atuantes na Atenção Primária há seis meses ou mais, e o critério de exclusão foi retirar do estudo aqueles que estavam de férias (ou licença de trabalho) durante o período/ processo de coleta de dados. Desta forma participaram deste estudo dez ACS, que se colocaram à disposição da pesquisa, assim como nove enfermeiros e uma equipe de Estratégia de Saúde da Família, composta por: um médico, um dentista, uma técnica em saúde bucal e três técnicas de enfermagem, todos servidores da secretaria saúde do município de Pinhalzinho/SC. Os profissionais foram divididos em grupos, equipe ESF (grupo 1), equipe enfermeiros (grupo 2) e ACS (grupo 3).

O presente estudo foi aprovado pelo Comitê de Ética em Pesquisas Envolvendo Seres Humanos da Universidade do Estado de Santa Catarina - CEPSH/ UDESC, parecer número 4.437.069 de 03 de dezembro de 2020. Todos os participantes concordaram em participar mediante aprovação no Termo de Consentimento Livre e Esclarecido (TCLE). A seguir apresentam-se as etapas do desenvolvimento do jogo:

- Definição do modelo do jogo: o arquétipo do jogo foi escolhido a partir de uma pesquisa/busca 
no site google, com os seguintes termos/formas: "jogo" + "saúde" + "tabuleiro" e "board game" + "health". A partir dessa busca encontrou-se sete modelos de jogos de tabuleiro, e destes foram selecionados três, cujo o critério utilizado foi ser um jogo composto por tabuleiro, carta e que possa ser jogado individualmente ou em equipe. Os três modelos selecionados foram apresentados e debatidos por todos os profissionais da equipe de ESF (grupo 1), em um encontro realizado na sala de reunião de uma UBS. Nesse encontro o Grupo 1 escolheu o modelo considerado mais adequado. Também foram encaminhados os modelos dos jogos de tabuleiro para as enfermeiras (grupo 2), para avaliação e aprovação do modelo. Esse momento aconteceu de forma virtual, por meio de um aplicativo de mensagens, devido questões de isolamento da pandemia do Coronavírus (COVID-19). De forma unânime entre as participantes dos grupos 1 e 2, escolheram o modelo, e este serviu de inspiração para a construção do jogo proposto.

- Definição do conteúdo do jogo: para a elaboração do conteúdo do jogo de tabuleiro foi realizado uma revisão narrativa da literatura nas bases de dados das ciências da saúde: PUBMED, Biblioteca Virtual em Saúde, Scopus, Google Acadêmico, Organização Mundial da Saúde (OMS), Organização Pan-Americana da Saúde (OPAS), Associações e demais setores envolvidos com a temática. Em relação à terminologia para a busca foram utilizados os seguintes descritores em português e inglês: jogo/ game; autismo/autism; sinais e sintomas/signals and symptons e diagnótico/diagnosis.

Os estudos encontrados nessas bases de dados foram transpostos para uma matriz/planilha, com as informações sobre autores, ano de publicação, e sinais de TEA. Foram incluídos os materiais publicizados em: artigos, relato de experiências, editoriais, documentários, notas técnicas, entre outros. Com até dez anos de publicação, em diferentes idiomas. Já a exclusão, se deu quando o conteúdo, após (re)leituras não atendiam de forma satisfatória os objetivos da revisão.

Além do conteúdo textual, o jogo de tabuleiro necessitou de figuras/imagens. Por isso, também foi selecionado pelas pesquisadoras imagens lúdicas de crianças que simbolizam o autismo no google imagens
(https://www.google.com/imghp?hl=pt-BR). Essas imagens serviram de base/inspiração para o designer (contratado para esse estudo) criar as figuras do tabuleiro.

Após definição, participativa dos enfermeiros e da equipe de ESF, do conteúdo e imagens, iniciou-se o processo de construção do jogo tabuleiro. Nesse momento teve a participação de uma profissional de designer para realização da arte gráfica.

- Validação do Jogo de Tabuleiro - identificando sinais de Transtorno do Espectro do Autismo: nessa etapa foi realizada a validação pelos profissionais da APS de forma individual. Os participantes receberam além do jogo de tabuleiro, um questionário para ser respondido após a testagem do jogo. Em vista de que não foi encontrado nenhum instrumento de validação especificamente para jogos de tabuleiro, adequou-se para esse fim, o instrumento EGameFlow ${ }^{(9)}$ por ser considerado apropriando para medir a satisfação de jogos educativos.

Nessa fase, os participantes avaliaram a relevância e a semântica do jogo de tabuleiro, os profissionais escolheram as seguintes respostas para cada questionamento do instrumento avaliativo: 1 = item relevante ou representativo, 2 = item necessita de pequena revisão para ser representativo, 3 = item necessita de grande revisão para ser representativo, ou 4 = não relevante ou não representativo. ${ }^{(10)}$ Para calcular o Índice de Validade de Conteúdo (IVC), foi aplicado uma escala tipo Likert de 4-pontos ordinais. Assim, o cálculo adotado foi feito a partir da somatória das respostas " 1 " e " 2 " de cada participante em cada item do questionário e divide-se esta soma pelo número total de respostas, como segue. ${ }^{(11)}$

$$
\text { IVC }=\frac{\text { Número de respostas " } 1 \text { " ou " } 2 \text { " }}{\text { Número total de respostas }}
$$

O IVC avalia a proporção ou porcentagem de participantes que concordam com determinado item do instrumento de coleta de dados/questionário possibilitando validação do instrumento por item e/ou de forma geral. ${ }^{(11)}$ Os itens que recebem resposta " 3 " ou " 4 " foram revisados ou eliminados, a partir das sugestões propostas pelos participantes que responderam o questionário. A taxa de concordância que foi aceitável entre os profissionais para avaliação dos itens individualmente foi superior a 0,7840 . Para a verificação da 
validade do novo instrumento de uma forma geral, deveria haver uma concordância mínima de 0,8036 e, preferencialmente superior a 0,9040. Além do questionário, foi incluída a seguinte questão "você tem alguma crítica e/ou sugestão referente ao produto?".

- Avaliação do conteúdo de texto e imagens do jogo: o conteúdo passou por avaliação nove enfermeiros, um médico, um dentista, um auxiliar de saúde bucal e três técnicas de enfermagem. Estes avaliaram o conteúdo pelo Método Painel de Desenvolvimento de Consenso. Trata-se de uma abordagem direcionada ao desenvolvimento de um consenso pela equipe participante do estudo. Foi realizado uma roda de conversa, cujo local foi numa sala de reunião de uma Unidade Básica de Saúde. O conteúdo selecionado para avaliação foi apresentado em forma de tópicos numa apresentação em powerpoint. Nesse momento foi verificado cada tópico, avaliando a adequação de linguagem e de concordância entre os participantes. Quando não houve consenso dos participantes sobre o tópico, foram debatidas sugestões e, de imediato, realizado alterações. Quanto às figuras do jogo, elas foram expostas para os participantes, três por vez, sendo que, a escolha das imagens foi debatida e consensuada segundo o contexto do jogo.

- Avaliação da interface do Jogo de Tabuleiro: nessa etapa, foi reunido cada grupo (1, 2 e 3) numa sala da secretaria de saúde, seguindo as normas de prevenção do coronavírus, para assim avaliar a estrutura física do jogo. Nesse momento foi explicada a dinâmica da tecnologia educativa criada e, na sequência, praticado o jogo. O jogo é composto por um tabuleiro, 42 cartas, um manual, seis peões e um dado. Ao término do jogo foi aplicado um questionário elaborado pelas pesquisadoras com base no EgameFlow. ${ }^{(9)}$ Após esse momento, foi realizado uma roda de conversa com os participantes da pesquisa para ajustes, no momento todos os participantes explanaram seu ponto de vista a partir da questão do que pensam em relação as regras, aparência e dinâmica do jogo. Assim, com essas sugestões dos participantes, foram realizadas mudanças/adequações do produto por consenso de toda a equipe e/ou grupo, e com a versão final do tabuleiro após avaliação, o mate- rial foi encaminhado para a profissional de designer realizar os ajustes da arte gráfica. O processo de produção do Jogo de Tabuleiro Identificando Sinais do Transtorno do Espectro do Autismo perdurou oito meses.

\section{Resultados}

O jogo de tabuleiro foi desenvolvido nas seguintes etapas: definição do modelo do jogo, definição do conteúdo e imagem do jogo, validação do Jogo de Tabuleiro, avaliação do conteúdo (texto e imagens) e avaliação da estrutura física "Identificando Sinais de Transtorno do Espectro do Autismo". Na etapa de definição do modelo do Jogo foi selecionado o layout com o tabuleiro de trilhos retos, casas especiais e um ponto de partida, que foi comparado com um tabuleiro com trilhos curvados e outro com trilhos retos, porém com 6 pontos de partida. A definição de conteúdo foi relacionada aos sinais de TEA em relação a interação social, linguagem, alimentação e brincadeiras nas idades de 0 á 6 meses, 6 á 12 meses, de 12 á 18 meses, de 18 á 24 meses e de 24 á 36 meses, ou seja, de 0 á 3 anos de idade. $\mathrm{Na}$ etapa de validação do jogo de tabuleiro, os profissionais avaliaram a jogabilidade e semântica (aparência, cores e formas). Após essa primeira experiência com o Jogo, os três grupos de profissionais participaram do processo de validação. O quadro 1 apresenta os resultados da validação.

O jogo de tabuleiro obteve uma nota de IVC de 0,9615 , evidenciando sua validação. Além disso, ao final da validação do Jogo de Tabuleiro, os profissionais manifestaram uma experiência proveitosa com a tecnologia educacional: "Parabéns pelo Jogo", "Trabalho maravilhoso, muito criativo, acredito que vai levar muita informação e aprendizado de forma didática e divertida referente a um tema tão pouco discutido e de tanta relevância", "Muito bom, dinâmico, dá vontade de jogar mais". Após o processo de validação foi realizado a avaliação do jogo. A avaliação de conteúdo do jogo, teve a participação de 25 profissionais, que debateram e sugeriram, de forma consensual, mudanças textuais do Jogo de Tabuleiro. Como observa-se no quadro 2.

Após as alterações/adequações de conteúdo, o material do jogo foi encaminhado para uma profissio- 
Quadro 1. Apresentação da pontuação da validação dos profissionais enfermeiros (9), equipe de ESF (6) e ACS (10) sobre o Jogo de Tabuleiro Identificando Sinais de TEA, tecnologia educativa voltada aos ACS

\begin{tabular}{|c|c|c|c|}
\hline \multirow[b]{2}{*}{ Questões } & \multicolumn{3}{|c|}{ IVC } \\
\hline & $\begin{array}{l}\text { Enfermeiros } \\
\text { (9) }\end{array}$ & $\begin{array}{c}\text { Profissionais de ESF } \\
(6)\end{array}$ & $\begin{array}{l}\text { ACS } \\
(10)\end{array}$ \\
\hline 0 jogo é fácil? & 1,0 & 1,0 & 1,0 \\
\hline 0 jogo é agradável de se jogar? & 1,0 & 1,0 & 1,0 \\
\hline 0 jogo é instigante? & 1,0 & 1,0 & 1,0 \\
\hline 0 jogo aprimora 0 conhecimento? & 1,0 & 1,0 & 1,0 \\
\hline 0 jogo prende minha atenção? & 1,0 & 1,0 & 1,0 \\
\hline Apresenta conteúdo que estimula minha atenção? & 1,0 & 1,0 & 1,0 \\
\hline Aproveito o jogo sem ficar entediado ou ansioso? & 0,88 & 1,0 & 1,0 \\
\hline Dificuldade é adequada? & 1,0 & 1,0 & 1,0 \\
\hline Existem “dicas” que ajudam na tarefa? & 1,0 & 1,0 & 1,0 \\
\hline Minhas habilidades aumentam conforme o jogo avança? & 1,0 & 1,0 & 1,0 \\
\hline Sou motivado pela melhora das minhas habilidades? & 1,0 & 1,0 & 1,0 \\
\hline Objetivos gerais apresentados no início do jogo? & 1,0 & 1,0 & 1,0 \\
\hline Objetivos gerais apresentados claramente? & 1,0 & 1,0 & 1,0 \\
\hline Recebo feedback do meu progresso no jogo? & 1,0 & 1,0 & 1,0 \\
\hline Recebo feedback imediato das minhas ações? & 1,0 & 1,0 & 1,0 \\
\hline Sou notificado sobre novas tarefas imediatamente? & 1,0 & 1,0 & 1,0 \\
\hline Recebo informação sobre sucesso ou falha de objetivos intermediários imediatamente? & 1,0 & 1,0 & 1,0 \\
\hline Recebo informação sobre o meu status, como nível ou pontuação? & 1,0 & 1,0 & 1,0 \\
\hline Me sinto cooperativo com outros colegas? & 1,0 & 1,0 & 1,0 \\
\hline Cooperação no jogo auxilia no aprendizado? & 1,0 & 1,0 & 1,0 \\
\hline 0 jogo melhora meu conhecimento? & 1,0 & 1,0 & 1,0 \\
\hline Capto as ideias básicas do conteúdo apresentado? & 1,0 & 1,0 & 1,0 \\
\hline Tento aplicar o conhecimento no jogo? & 1,0 & 1,0 & 1,0 \\
\hline 0 jogo motiva o jogador a integrar o conteúdo apresentado? & 1,0 & 1,0 & 1,0 \\
\hline Quero saber mais sobre o conteúdo apresentado? & 1,0 & 1,0 & 1,0 \\
\hline As regras do jogo estão claras? & 0,77 & 1,0 & 1,0 \\
\hline
\end{tabular}

Quadro 2. Avaliação da equipe multiprofissional sobre o conteúdo do Jogo de Tabuleiro Identificando Sinais de TEA, tecnologia educativa voltada aos ACS

\begin{tabular}{|c|c|c|}
\hline Cartas $\mathrm{n}^{\circ}$ & Carta na versão de avaliação & Carta na versão final \\
\hline 2 & $\begin{array}{l}\text { R: Interação Social: } 0 \text { bebê com TEA pode não buscar e acompanhar } 0 \\
\text { olhar de seu cuidador ou faz com uma frequência menor. }\end{array}$ & $\begin{array}{l}0 \text { bebê com Transtorno do Espectro do Autismo pode não buscar e } \\
\text { acompanhar o olhar de seu cuidador ou faz com uma frequência menor. }\end{array}$ \\
\hline 4 & $\begin{array}{l}\text { P: Linguagem: Desde o nascimento, a criança parece prestar atenção à } \\
\text { melodia da fala humana. Após os } 3 \text { meses, ela já identifica a fala de seu } \\
\text { cuidador, apresentando reações corporais, e para os sons ambientais, } \\
\text { apresenta expressões, por exemplo, de choro, "susto" e tremor. }\end{array}$ & $\begin{array}{l}\text { Linguagem: Desde o nascimento, a criança parece prestar atenção à } \\
\text { melodia da fala humana. Após o } 3^{\circ} \text { mês, o bebê já identifica a fala de seu } \\
\text { cuidador, apresentando reações corporais, e para os sons ambientais, o } \\
\text { bebê apresenta expressões de choro, "susto" e tremor. }\end{array}$ \\
\hline 5 & $\begin{array}{l}\text { P: Linguagem: Desde o começo, o bebê apresenta balbucio indiscriminado } \\
\text { e intenso, bem como gritos de forma aleatória, de volume e intensidade } \\
\text { variada, na presença ou na ausência de um cuidador. Aos } 6 \text { meses, } \\
\text { começa uma discriminação nas produções sonoras, que tendem a } \\
\text { aparecer principalmente na presença do cuidador. }\end{array}$ & $\begin{array}{l}\text { A carta foi excluída por consenso pela equipe de ESF, por ela ser parecida } \\
\text { com a carta número } 6 .\end{array}$ \\
\hline 7 & $\begin{array}{l}\text { P: Alimentação: A amamentação é um momento privilegiado de atenção } \\
\text { por parte da criança, às expressões faciais, aos gestos, e à fala de seu } \\
\text { cuidador. }\end{array}$ & $\begin{array}{l}\text { Alimentação: A amamentação é um momento privilegiado de atenção em } \\
\text { que existe o olho no olho entre a mãe e o bebe, expressões faciais e gestos } \\
\text { do recém-nascido perante a fala do seu cuidador. }\end{array}$ \\
\hline 7 & $\begin{array}{l}\text { R: Alimentação: A criança com Transtorno do Espectro do Autismo, pode } \\
\text { apresentar dificuldades nesses aspectos. }\end{array}$ & $\begin{array}{l}\text { Alimentação: A criança com Transtorno do Espectro do Autismo, pode } \\
\text { apresentar dificuldades no aspecto relacionado à atenção ao cuidador. }\end{array}$ \\
\hline 8 & $\begin{array}{l}\text { R: Interação social: Crianças com Transtorno do Espectro do Autismo, } \\
\text { podem apresentar dificuldades para esses comportamentos. }\end{array}$ & $\begin{array}{l}\text { Interação social: Crianças com Transtorno do Espectro do Autismo podem } \\
\text { apresentar dificuldades nos comportamentos antecipatórios como também } \\
\text { de imitar. }\end{array}$ \\
\hline 11 & $\begin{array}{l}\text { R: Linguagem: Crianças com Transtorno do Espectro do Autismo, tendem a } \\
\text { não agir como se conversassem. }\end{array}$ & $\begin{array}{l}\text { Linguagem: Crianças com Transtorno do Espectro do Autismo, tendem a } \\
\text { não agir como se conversassem. Os bebês não prestam atenção na fala } \\
\text { materna, e não respondem com gritos, balbucios, movimentos corporais. }\end{array}$ \\
\hline 17 & $\begin{array}{l}\text { R: Linguagem: A criança com Transtorno do Espectro do Autismo, pode não } \\
\text { apresentar as primeiras palavras nesta faixa de idade. }\end{array}$ & $\begin{array}{l}\text { Linguagem: A criança com Transtorno do Espectro do Autismo, pode não } \\
\text { apresentar as primeiras palavras em repetição à fala de outras pessoas } \\
\text { nesta faixa de idade. }\end{array}$ \\
\hline
\end{tabular}




Continuação.
\begin{tabular}{|l|l|l|}
\hline Cartas n & Carta na versão de avaliação & Carta na versão final \\
\hline 18 & $\begin{array}{l}\text { P: Linguagem: A partir dos } 12 \text { meses a criança desenvolve mais } \\
\text { amplamente a fala, com um uso gradativo e mais apropriado do } \\
\text { vocabulário e da gramática. Há um progressivo descolamento de usos } \\
\text { "congelados” das palavras para um movimento livre na fala. }\end{array}$ & $\begin{array}{l}\text { Linguagem: A partir dos 12 meses a criança desenvolve mais amplamente } \\
\text { a fala, com um uso gradativo e mais apropriado do vocabulário e da } \\
\text { gramática. Há um progressivo movimento livre na fala. }\end{array}$ \\
\hline 27 & $\begin{array}{l}\text { R: Linguagem: A criança com Transtorno do Espectro do Autismo, tende à } \\
\text { ecolalia. }\end{array}$ & $\begin{array}{l}\text { Linguagem: A criança com Transtorno do Espectro do Autismo, tende à } \\
\text { ecolalia, ou seja, fala repetitiva. }\end{array}$ \\
\hline 35 & $\begin{array}{l}\text { R: Linguagem: A criança com Transtorno do Espectro do Autismo, } \\
\text { geralmente tende à ecolalia. A distinção de gênero, número e tempo não } \\
\text { acontece. Cantos e versos só são recitados em repetição aleatória. A } \\
\text { criança não “conversa” com o adulto. }\end{array}$ & $\begin{array}{l}\text { Linguagem: A criança com Transtorno do Espectro do Autismo, geralmente } \\
\text { tende à ecolalia, ou seja, fala repetitiva. A distinção de gênero, número } \\
\text { e tempo não acontece. Cantos e versos só são recitados em repetição } \\
\text { aleatória. A criança não “conversa” com o adulto. }\end{array}$ \\
\hline 39 & $\begin{array}{l}\text { P: Alimentação: A partir dos 24 meses a criança já participa das cenas } \\
\text { alimentares cotidianas: café da manhã, almoço e jantar. É capaz de } \\
\text { estabelecer separação dos alimentos pelo tipo de refeição ou situação, } \\
\text { como por exemplo, comida de lanche, festa, almoço de domingo etc. Se } \\
\text { tem o inicio do manuseio adequado dos talheres. A alimentação está } \\
\text { contida ao longo do dia. }\end{array}$ & $\begin{array}{l}\text { Alimentação: A partir dos 24 meses a criança já participa das cenas } \\
\text { alimentares cotidianas: café da manhã, almoço e jantar. É capaz de } \\
\text { estabelecer separação dos alimentos pelo tipo de refeição ou situação, } \\
\text { como por exemplo, comida de lanche, festa, almoço de domingo etc. Se } \\
\text { inicia o manuseio adequado dos talheres. A alimentação está contida ao } \\
\text { longo do dia. }\end{array}$ \\
\hline
\end{tabular}

Obs: o P representa a carta pergunta e o $\mathrm{R}$, representa a carta resposta

nal de designer para realizar a arte final. A participação da equipe multiprofissional na avaliação do conteúdo foi de extrema importância para o aprimoramento do jogo de tabuleiro, pois eles realizaram sugestões baseadas em evidências e vivências profissionais. Diante dos resultados positivos, o Jogo de Tabuleiro Identificando Sinais de Transtorno do Espectro do Autismo foi implementado na APS ao programa de educação continuada, sendo disponibilizado a todas as sete equi-

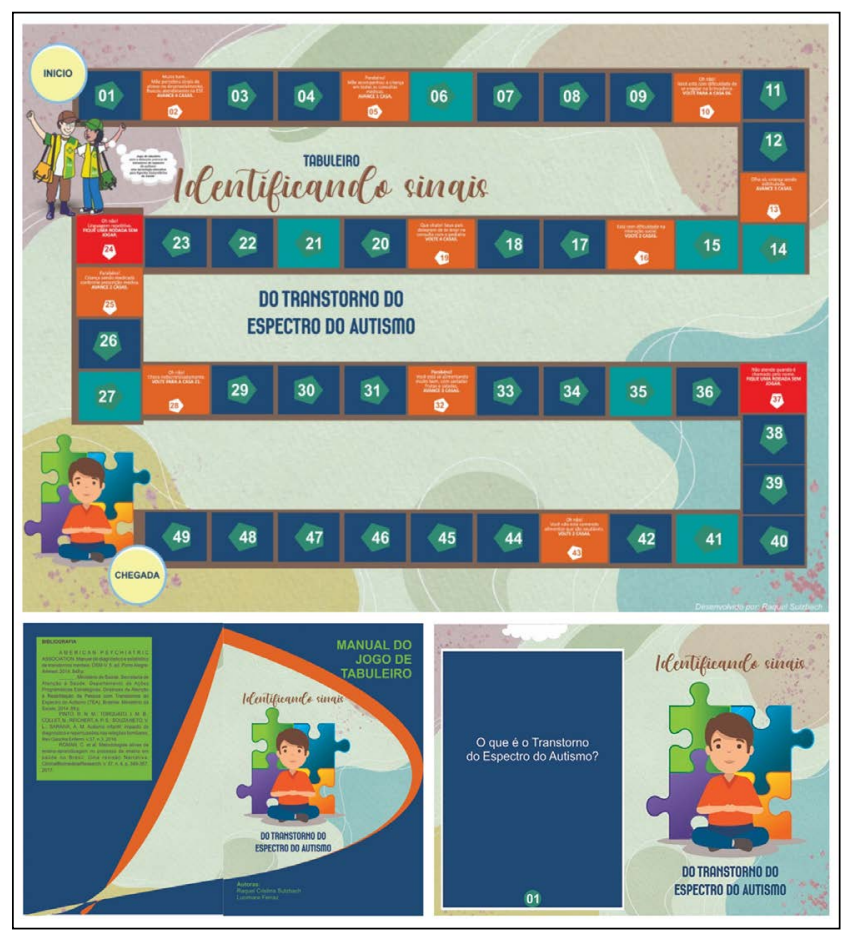

Figura 1. Interfaces do Jogo de Tabuleiro Identificando Sinais do Transtorno do Espectro do Autismo produzido para Agentes Comunitários de Saúde. pes de ESF do município para uso nas capacitações de ACS e em grupos de pré-natal. Destaca-se ainda, que o Jogo de Tabuleiro está à disposição dos professores das escolas públicas do Município, considerando que esse profissional também pode contribuir com a identificação de crianças portadoras de TEA. Outrossim, o mesmo pode ser acessado na página do Mestrado Profissional em Enfermagem na Atenção Primária à Saúde da Universidade do Estado de Santa Catarina - UDESC.

\section{Discussão}

A construção de um instrumento para educação em saúde do tipo Jogo de Tabuleiro para capacitar ACS, vem ao encontro de estudos recentes, que têm comprovado a eficácia da utilização da estratégia de jogos educacionais para os processos de ensino e aprendizagem. ${ }^{(12-15)}$

As tecnologias em saúde, especialmente as de enfermagem, apresentam avanços evidentes quando se fala em cuidado, e têm como objetivo a melhora direta na prestação de atendimento ao paciente e seus familiares. ${ }^{(12,15)}$ É importante que as tecnologias educacionais apresentem conteúdos verídicos, embasados a partir do conhecimento científico, visando aumentar a credibilidade e demonstrar o comprometimento com o processo de desenvolvimento do conhecimento. ${ }^{(16)}$ Por isso, as metodologias de ensino, utilizadas para educação em saúde, necessitam ser atrativas e inovadoras para atingir um bom resultado, melhorando o 
conhecimento e qualificando o trabalho. Assim, o uso de jogos apresenta-se como uma boa alternativa.

A validação e avaliação do Jogo de Tabuleiro por parte do público-alvo foi essencial, evidenciando que quando o processo é realizado de modo participativo, é possível obter várias considerações sobre a atividade, o material, sua relevância. Isso permite aos participantes opinarem e intervirem para melhorias que podem ser feitas para aperfeiçoamento da tecnologia. Observou-se também que os participantes se mostraram estimulados a continuar a discussão sobre o assunto do TEA, após jogar o jogo demonstrando que a tecnologia despertou interesse pelo tema, sendo enriquecedora e fundamental para o aprimoramento e qualificação dos jogadores/participantes. A pesquisa participativa, no modo de primeira "densidade", o público-alvo é partícipe da etapa de validação semântica e/ou de aparência; entrando em contato direto com a tecnologia e podem manifestar sua opinião contribuindo no aperfeiçoamento da tecnologia. ${ }^{(8)}$

Em relação as características gerais do jogo, como layout e conteúdo, ele foi validado como excelente. Acredita-se que o parecer do jogo esteja associado ao processo de desenvolvimento, que envolveu uma equipe multiprofissional, sendo de extrema importância esse olhar interdisciplinar importante para a sua construção e aprimoramento. As contribuições realizadas por uma equipe interdisciplinar são fundamentais para o desenvolvimento de tecnologias, pois enriquecem o processo com os seus conhecimentos e vivências. ${ }^{(17)}$

O instrumento também passou pela validação, e este, foi considerado adequado pelos profissionais e trabalhadores participantes, obtendo um IVC com valor considerado plenamente satisfatório para as tecnologias educacionais. ${ }^{(18)} \mathrm{O}$ processo de validação do material é relevante, ${ }^{(19)}$ por isso as questões que atingiram um IVC menor foram readequadas/ajustadas a partir das sugestões. Assim, pode-se dizer, que o procedimento adotado foi enriquecedor e essencial para aprimoramento e qualificação da tecnologia.

Quanto ao conteúdo do TEA abordado na tecnologia construída, entende-se que é um tema pouco explorado quando se trata em transmitir informações sobre esse agravo aos pais e/ou familiares, muito provável, pelo fato de que pode causar tristeza. ${ }^{(20)}$ Por isso, da importância de esclarecer mais sobre essa temática para que no momento em que a família for abordada na APS, os profissionais e trabalhadores tenham propriedade e conhecimento para orientá-los da melhor maneira.

Os ACS, em seus debates, expressaram que o Jogo de Tabuleiro Identificando Sinais do Transtorno do Espectro do Autismo é uma tecnologia que aprimorou o conhecimento. Esse fato, corrobora com estudos semelhantes que também avaliaram a melhoria de informação por meio de jogos educativos. ${ }^{(17)}$ Assim, acredita-se que essa tecnologia contribui para a capacitação dos ACS no cuidado às crianças com TEA, pois os jogos educativos têm o potencial em aumentar o interesse, e estimular a interatividade e a motivação, com impacto positivo no processo ensino e aprendizagem.

Por fim, destaca-se a importância do trabalho interdisciplinar para o desenvolvimento de tecnologias que exigem outras habilidades dos profissionais de saúde, como a parte gráfica e de desenho. Cabe frisar que tempo de construção do jogo de tabuleiro -que perdurou oito meses- poderia ter sido menor, se sua construção fosse centrada somente no conhecimento dos pesquisadores, mas, com certeza, não teria sido um processo exitoso, pois as vivências e experiências dos profissionais da saúde que fazem o atendimento de crianças foram fundamentais para o desenvolvimento dessa tecnologia educativa.

Como limitação do estudo, menciona-se que o jogo de tabuleiro foi testado em apenas um município, assim questões de linguagem e culturas locais podem ter interferido na semântica das palavras do conteúdo.

\section{Conclusão}

O desenvolvimento deste estudo possibilitou apresentar um processo de construção, validação e avaliação de uma tecnologia educativa voltada para o diagnóstico precoce do Transtorno do Espectro do Autismo. Essa pesquisa foi elaborada de modo participativo por uma equipe multiprofissional além de ser fundamentada em bases científicas. A equipe multiprofissional foi composta principalmente por profissionais enfermeiros, que são coordenadores da Atenção Primária à Saúde e experientes no atendimento às crianças de todas as idades. A metodologia empregada nesse estudo mostrou-se capaz de subsidiar a elaboração de uma 
tecnologia educativa atrativa e compreensiva. O Jogo de Tabuleiro é uma estratégia educativa relevante, pois demonstrou-se capaz de propiciar conhecimentos aos ACS em relação aos sinais do TEA em crianças e, assim, melhorar a detecção precoce. Cabe frisar que os ACS estão próximos das famílias, acompanhando o crescimento e desenvolvimento das crianças, identificando déficits e levando as demandas de cuidado para as equipes de saúde; que de posse das informações interveem e assistem com maior brevidade as crianças com TEA.

\section{Contribuições}

Sulzbach RC, Ferraz L, Zanatta L, Lutinski JA contribuíram com a concepção do projeto, análise e interpretação dos dados, redação do artigo, revisão crítica relevante do conteúdo intelectual e aprovação da versão final a ser publicada.

\section{Referências}

1. Sadock JB, Sadock VA, Ruiz P. Compêndio de Psiquiatria: Ciência do Comportamento e Psiquiatria Clínica. 11. ed. Porto Alegre: Artmed; 2017.

2. World Health Organization (WHO). Autism spectrum disorders. Genève: WH0; 2019 [cited 2021 Jan 20]. Available from http://www.who.int/news-room/fact-sheets/detail/autismspectrum-disorders

3. Pretzsch MC, Freyberg J, Voinescu B, Lythgoe D, Horder J, Mendez MA, et al. Effects of cannabidiol on brain excitation and inhibition systems; a randomised placebo-controlled single dose trial during magnetic resonance spectroscopy in adults with and without autism spectrum disorder. Neuropsychopharmacology. 2019;44:1398-405.

4. Silva Junior JC, Mota LM. 0 papel do enfermeiro na identificação precoce do transtorno do espectro autista na atenção primária. Centro Universitário Tiradentes-UNIT/AL: Alagoas; 2021.
5. Brasil. Ministério da Saúde. Portaria ${ }^{0} 2.436$ de 21 de setembro de 2017. Aprova a Política Nacional de Atenção Básica, estabelecendo a revisão de diretrizes para a organização da Atenção Básica, no âmbito do Sistema Único de Saúde (SUS). Brasília (DF): Ministério da Saúde; 2017.

6. Machado TP, Ensslin L, Ensslin SR. Desenvolvimento de produtos usando a abordagem MCDA-C. Prod. 2015;25(3):542-59.

7. Roman C, Ellwanger J, Becker GC, Silveira AD, Machado CL, Manfroi WC. Metodologias ativas de ensino-aprendizagem no processo de ensino em saúde no brasil: uma revisão narrativa. Clin Biomed Res. 2017;37(4):349-57.

8. Teixeira, E. (Org) Desenvolvimento de Tecnologias cuidativo-educacionais. $2^{\mathrm{a}}$ ed. Porto Alegre: Moriá, 2020.

9. Fu FL, Su RC, Yu SC. EGameFlow: Uma escala para medir o prazer dos alunos em jogos de e-learning. Computadores Educ. 2009; 52(1):101-12.

10. Wynd CA, Schaefer MA.A ferramenta de avaliação de risco de osteoporose: Estabelecendo a validade de conteúdo por meio de um painel de especialistas. Pesq Enferm Apl. 2002;15(3):184-8.

11. Alexandre NM, Coluci MZ. Validade de conteúdo nos processos de construção e adaptação de instrumentos de medidas. Ciênc Saúde Coletiva. 2011;16(7):3061-8.

12. DalmolinA,Girardon-Perlini NM,CoppettiLC,RossatoGC,GomesJS,SilvaME.Educationalvideo as a healthcare education resource for people with colostomy and their families. Rev Gaúcha Enferm. 2016;37(esp):e68373.

13. Harrison D, Reszel J, Dagg B, Aubertin C, Bueno M, Dunn S, et al. Pain Management During Newborn Screening: Using YouTube to Disseminate Effective Pain Management Strategies. 2017;31(2): 172-7.

14. Razera AP, Trettene AS, Mondini CC, Cintra FM, Tabaquim ML. Education vídeo: a training strategy for caregivers of children with cleft lip and palate. Acta Paul Enferm. Acta Paul Enferm. 2016; 29(4):430-8.

15. O'Sullivan TA, Cooke J, McCafferty C, Giglia R. Online Video Instruction on Hand Expression of Colostrum in Pregnancy is an Effective Educational Tool. Nutrients. 2019;11(4):883.

16. Toneti BF. Desenvolvimento e validação de tecnologias digitais voltadas ao ensino de uma prática integrativa e complementar em saúde [dissertação]. São Paulo: Universidade de São Paulo; 2019.

17. Castro TC, Gonçalves LS. 0 uso da gamificação para o ensino da enfermagem. Rev Bras Enferm. 2018;71(3):1038-45.

18. Benevides JL, Coutinho JF, Pascoal LC, Joventino ES, Martins MC, Gubert FA, et al. Desenvolvimento e validação de tecnologia educacional para tratamento de úlceras venosas. Rev Esc Enferm USP. 2016;50(2):309-16.

19. Tenório AP. Construção de validação de um website sobre cuidados com 0 prematuro [dissertação]. Recife: Universidade Federal de Pernambuco; 2016.

20. Pinto RN, Torquato IM, Collet N, Reichert AP, Souza Neto VL, Saraiva AM. Autismo infantil: impacto do diagnóstico e repercussões nas relações familiares. Rev Gaúcha de Enferm. 2016;37(3):e61572. 